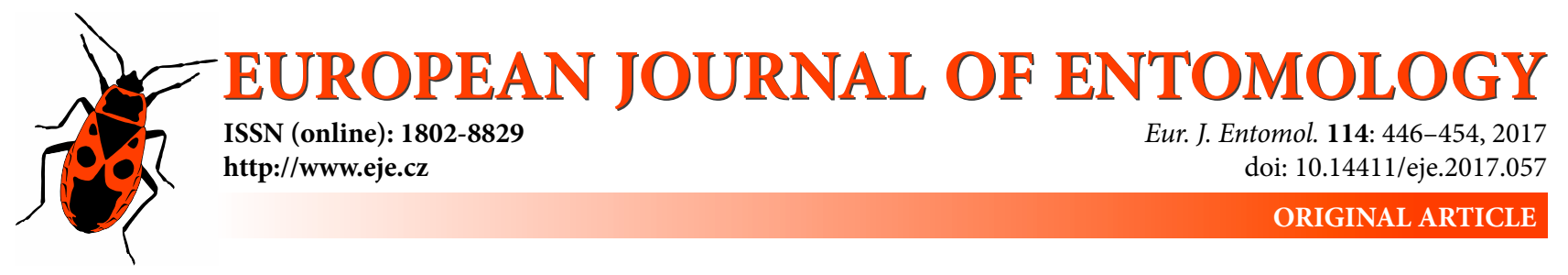

\title{
Preliminary evidence of the horizontal transmission of Wolbachia between Crioceris leaf beetles (Coleoptera: Chrysomelidae) and their Asparagus host plants
}

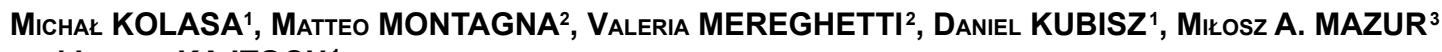 \\ and KUKASZ KAJTOCH ${ }^{1}$ \\ ${ }^{1}$ Institute of Systematics and Evolution of Animals, Polish Academy of Sciences, Krakow, Poland; \\ e-mails: michal.r.kolasa@gmail.com, kubisz@isez.pan.krakow.pl, lukasz.kajtoch@gmail.com \\ 2 Università degli Studi di Milano, Dipartimento di Scienze Agrarie e Ambientali, Milan, Italy; e-mails: matteo.montagna@unimi.it, \\ valeria.mereghetti@unimi.it \\ ${ }^{3}$ Center for Biodiversity Studies, Department of Biosystematics, Opole University, Opole, Poland; \\ e-mail: mazurmilosz@gmail.com
}

Key words. Alpha-Proteobacteria, Wolbachia, Coleoptera, Chrysomelidae, Crioceris, Asparagus, molecular ecology, horizontal transmission, Multilocus Sequence Typing

\begin{abstract}
Intracellular bacteria of the genus Wolbachia ( $\alpha$-Proteobacteria) are the most widespread endosymbionts of insects. Host infection is usually associated with alterations in reproduction, such as cytoplasmic incompatibility, the induction of parthenogenesis and offspring sex ratio bias: all phenomena that may influence host speciation. In the present study, by using wellestablished molecular tools, we investigated the presence of Wolbachia in leaf beetles of the genus Crioceris and their host plants, which are various species of Asparagus. Multilocus sequence typing of bacterial genes showed that despite their occurrence in the same habitat and feeding on the same plant, two species of Crioceris, C. quinquepunctata and C. quatuordecimpunctata, are infected by two different strains of Wolbachia. C. asparagi, C. paracenthesis and C. duodecimpunctata, which are sympatric with the infected species, do not harbour the bacterium. Interestingly, DNA of Wolbachia was detected in host plant tissues that are exploited by the beetles, providing evidence for the horizontal transmission of the bacterium between beetles and their host plants. Moreover, Wolbachia was detected in species of Crioceris that are not closely related.
\end{abstract}

\section{INTRODUCTION}

Wolbachia is a maternally-inherited, Gram-negative bacterium belonging to the $\alpha$-Proteobacteria (Riegler \& O’Neill, 2006), which infect Arthropoda (mostly insects and spiders) and Nematoda. Recently, the different $\mathrm{Wol}$ bachia supergroups were proposed to belong to several "Candidatus Wolbachia" species (Ramírez-Puebla et al., 2015); however, this approach was criticized (Lindsey et al., 2016). In recent years, aside from numerous studies that describe the vertical transmission of this bacterium to the progeny of infected beetles, and the spread of the bacterium within host populations through the distortion of the reproduction of their hosts (Breeuwer et al., 1992; O'Neil et al., 1992; Rousset et al., 1992; Stouthamer et al., 1993), evidence has emerged for its horizontal transmission between species, even between kingdoms (Vavre et al., 1999; Caspi-Fluger et al., 2012). The prevalence of Wolbachia in arthropods, including the detection of the same strain in unrelated species of arthropods, suggests the existence of a more complex scenario for transmitting this bacterium to hosts, one that is different from transmission from mother to offspring. It is believed that predators, parasitoids, shared habitats, and especially, a shared plant food source (e.g., plants or fungi) could make a species susceptible to infection (Sintupachee et al., 2006; Stahlhut et al., 2010). The possibility that Wolbachia could spread horizontally across food chains is highly debated, and evidence supporting this possibility has recently been provided by studies that detected DNA from the bacterium in uninfected predators that fed on infected prey (Johanowicz \& Hoy, 1996; Huigens et al., 2004; Clec'h et al., 2013). Moreover, it has been suggested that host-parasitoid interactions may be a mechanism for the spread of Wolbachia among species (Vavre et al., 1999). This hypothesis is supported by several studies (e.g. Van Meer et al., 1999; Noda et al., 2001; Ahmed et al., 2015). The transmission of this bacterium via a shared habitat or exploitation of infected plant material, such as leaves or roots, is a little investigated, possibility. Mitsuhashi et al. (2002) and Sintupachee et al. (2006) propose that Wolbachia could spread to other hosts by feeding 
on leaves previously fed on by infected organisms (CaspiFluger et al., 2012). Recent studies indicate that phloem sap may be the source of such a contagion (DeLay, 2012; Li et al., 2016). However, there are only a few studies that attempt to disentangle the trophic interactions between the bacterium, its host and host plants (Vavre et al., 1999; Fenton et al., 2011), and comprehensive studies including all these trophic levels are still scarce.

The genus Crioceris Geoffroy, 1762 (Coleoptera: Chrysomelidae), commonly known as asparagus beetles, consists of 62 species and is distributed nearly worldwide, with the exception of the Australian and Neotropical regions (Monrós, 1960). Among the described species of the genus, 22 are Palearctic and eight are present in Europe (Warchałowski, 1985; Löbl \& Smetana, 2010). All of the species in this genus are oligophagous or monophagous, feeding on perennial, salt-tolerant herbaceous plants, mainly belonging to the genus Asparagus (Clark et al., 2004). Due to their diet, Crioceris beetles are widely distributed and are a pest of cultivated Asparagus. Four species inhabit central and eastern Europe, namely $C$. asparagi (Linnaeus, 1758), C. duodecimpunctata (Linnaeus, 1758) [hereafter called C. 12-punctata], C. quatuordecimpunctata (Scopoli, 1763) [hereafter called C. 14-punctata] and C. quinquepunctata (Scopoli, 1763) [hereafter called C. 5-punctata]. Two of them, C. asparagi and C. duodecimpunctata, were accidentally introduced into North America (LeSage et al., 2008) and are serious pests of cultivated Asparagus. In contrast, Crioceris beetles are used in Australia to control Asparagus asparagoides, which is a non-native (Morin \& Edwards, 2006). C. 14-punctata and C. 5-punctata inhabit steppe and xerothermic habitats in central and eastern Europe and central and western Asia. Due to the loss of such habitats they have become endangered and in Europe are reported only at a few localities (Kubisz et al., 2012a; Mazur et al., 2014). The other three European species of Crioceris [C. paracenthesis (Linnaeus, 1767); C. bicruciata Sahlberg, 1823; C. macilenta Weise, 1880] are restricted to the Mediterranean Basin, except Crioceris paracenthesis, which is known from the Alpine region (Gruev, 2005) and tends to migrate to central Europe (Warchałowski, 1985); it is therefore sympatric at some locations with the above mentioned species. Moreover, the European species of Crioceris inhabit similar ecological niches, often living in the same habitats and localities. Despite these similarities, no hybrids between these leaf beetles occur in nature, even between the two sister species C. 12-punctata and $C$. 14-punctata (Kubisz et al., 2012b).

A preliminary genetic study confirmed that C. 12-punctata is the sister species of C. 14-punctata, as expected on the basis of their similar morphology, however the phylogenetic relations among the European species of this genus have not been fully resolved (Kubisz et al., 2012b). Interestingly, previous population genetic studies on the steppic C. 5-punctata and C. 14-punctata revealed that Wolbachia was present in all populations analyzed (Kubisz et al., 2012a; Mazur et al., 2014). Starting from these preliminary results, the purpose of the present study is to inves-

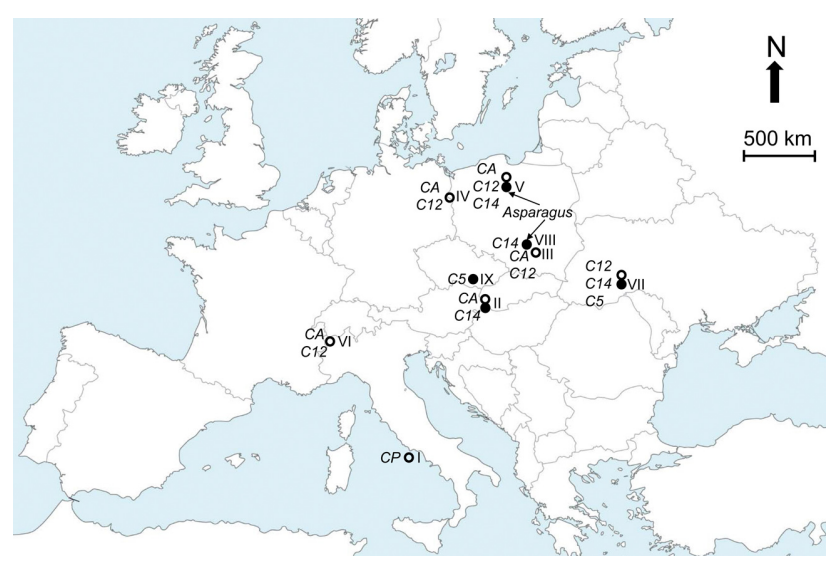

Fig. 1. Simplified map of Europe showing the locations of the sites where Crioceris beetles (CP - C. paracenthesis, CA - C. asparagi, C12 - C. quatuordecimpunctata, C14 - C. duodecimpunctata, C5 - C. quinquepunctata) and their Asparagus host plants were sampled. Open circles - sites without Wolbachia, solid circles - sites with infected beetles. Numbers (I-IX) correspond to site numbers described in Table 1.

tigate the presence of Wolbachia in the European species of the genus Crioceris and their host plants. Using a Multilocus Sequence Typing (MLST) approach, we test if the Wolbachia strains are geographically stable, if the strains are associated with closely related host beetles and if $\mathrm{Wol}$ bachia can be transmitted between beetles and their host plants.

\section{MATERIAL AND METHODS}

\section{Sampling}

Specimens of the five species of Crioceris studied (C. asparagi, C. 5-punctata, C. paracenthesis, C. 12-punctata, C. 14-punctata) were collected during several field trips in 2010 in Poland, Ukraine, Czech Republic and Slovakia, and in Italy in 2014 (Table 1, Fig. 1). In total, 77 individuals assigned to Crioceris (10 to 23 specimens per species, except $C$. paracenthesis; Table 1) were collected from several localities, avoiding species on cultivated Asparagus, and used in this study (Table 1). The sample size of the two steppic species (C. 5-punctata, C. 14-punctata) and C. paracenthesis was limited due to the rarity of these species, both

Table 1. Sampling sites of Crioceris species used in the study. In bold - Wolbachia infected species.

\begin{tabular}{|c|c|c|c|c|c|}
\hline $\begin{array}{l}\text { Site } \\
\text { no. }\end{array}$ & Species & Symbol & Country & Site & $\begin{array}{l}\text { No. of } \\
\text { spec. }\end{array}$ \\
\hline $\mathrm{I}$ & C. paracenthesis & $\mathrm{CP}$ & Italy & Isola di Ponza & 3 \\
\hline II & \multirow{5}{*}{ C. asparagi } & \multirow{5}{*}{ CA } & Slovakia & Devin & 4 \\
\hline III & & & Poland S & Wiślica & 5 \\
\hline IV & & & Poland N & Grabowo & 4 \\
\hline V & & & Poland W & Gozdowice & 5 \\
\hline $\mathrm{VI}$ & & & Italy & Aosta, Pont d'Ael & 4 \\
\hline$\overline{\mathrm{VII}}$ & \multirow{5}{*}{ C. duodecimpunctata } & \multirow{5}{*}{ C12 } & Ukraine & Lomachyntsi & 5 \\
\hline III & & & Poland S & Wiślica & 5 \\
\hline IV & & & Poland N & Grabowo & 5 \\
\hline V & & & Poland W & Gozdowice & 4 \\
\hline VI & & & Italy & Aosta, Pont d'Ael & 4 \\
\hline II & \multirow{4}{*}{$\begin{array}{c}\text { C. quatuor- } \\
\text { decimpunctata }\end{array}$} & \multirow{4}{*}{ C14 } & Slovakia & Devin & 5 \\
\hline VII & & & Ukraine & Lomachyntsi & 5 \\
\hline IV & & & Poland N & Grabowo & 4 \\
\hline VIII & & & Poland S & Skowronno & 5 \\
\hline $\mathrm{IX}$ & \multirow{2}{*}{ C. quinquepunctata } & \multirow{2}{*}{ C5 } & Czech R. & Pouzdrany & 5 \\
\hline VII & & & Ukraine & Lomachyntsi & 5 \\
\hline
\end{tabular}


in terms of populations and individuals sampled. Recent studies have shown that in central-eastern Europe there are only a few localities of these species (Kubisz et al., 2012; Mazur et al., 2014). Moreover, at each site only a few specimens were observed on single host plants (Asparagus officinalis). Consequently, sampling was limited to reduce its effects on these populations. Some specimens of C. 14-punctata were collected in northern (Kujawy Basin) and southern Poland (Nida Basin) in 2016, from the only known current locations of this species in this part of its range. From the same locations, fresh tissues of Asparagus officinalis, the host plant, were collected from plants that were infested with C. 14-punctata and/or C. 12-punctata. Samples were taken from only 2-4 plants at each locality as only a few such bushes were found, and from each bush we cut 2 leaves, 2 stems and 2 roots. In total, plant tissues were collected at the following three localities: (i) southern Poland (Skowronno) where C. 14-punctata was present; (ii) southern Poland (Wiślica) where C. 12-punctata was present and (iii) northern Poland (Grabowo) where both species of beetle were present. At all localities samples were taken during the spring and early summer (May/June), whereas in Skowronno additional samples were collected during mid-summer (July). Beetles were first preserved in $99 \%$ ethanol and then stored at $-22^{\circ} \mathrm{C}$, while plant tissues were preserved in plastic bags with silicat.

\section{Laboratory procedures}

Whole insect bodies were used for DNA extraction using a Nucleospin Tissue kit (Macherey-Nagel). The same was done for plant tissues using a Nucleospin Plant Tissue Kit (MachereyNagel). Prior to DNA extraction, beetles and plants were washed several times in $99 \%$ ethanol and distilled water to remove external contaminants. Moreover, plant tissues used for DNA extraction were cut from the inner part of leaves, stems or roots. DNA extraction from plant tissues was done under sterile conditions in order to avoid contamination from beetle extractions. For Wolbachia screening we used five standard MLST housekeeping genes: cytochrome $\mathrm{C}$ oxidase, subunit I $(\operatorname{cox} A)$, aspartyl/ glutamyl-tRNA(Gln) amidotransferase, subunit B (gatB), conserved hypothetical protein $(h c p A)$, fructose-bisphosphate adolase $(f b p A)$ and the cell division protein $(f t s Z)$ (Jolley \& Maiden, 2010) following the methods described by Baldo et al. (2006) Detection of Wolbachia was first done using primers for amplifying fts $Z$. All DNA isolates obtained from beetles and host plant tissues were amplified. Two random $f t s Z$-positive samples from each site (insects and plants) were subjected to amplification for the remaining MLST genes ( $g a t B, \operatorname{cox} A, h c p A$ and $f b p A$ ) according to protocols available at http://pubmlst.org/Wolbachia/. Since fts $Z$ sequences confirmed that Wolbachia from super groups A and $B$ are present in infected beetles, primers able to discriminate between these two super groups were used to obtain clear $\mathrm{A}$ and B sequences (http://pubmlst.org/Wolbachia/). All PCRs targeting Wolbachia were done using DNAs from Polydrusus inustus and Eusomus ovulum as a positive control. These species are known to be infected by Wolbachia (Mazur et al., 2016). For the host plants, DNA quality was assessed by amplification of chloroplast DNA using primers for the trnL intron. PCR amplification of a fragment of the mitochondrial cytochrome oxidase I (COI) gene was done using primer pairs C1-J-2183 and TL2-N-3014 (Simon et al., 1994). Additionally, the internal transcribed spacer 1 (ITS1) nuclear marker was amplified using primer pair ITS1 and ITS2 (White et al., 1990). PCRs were carried out using the concentration of reagents and thermal profile adopted in a previous study (Kubisz et al., 2012). After purification (NucleoSpin Extract II, Macherey-Nagel), the PCR fragments (both host and bacteria genes) were sequenced using a BigDye Terminator v.3.1.
Cycle Sequencing Kit (Applied Biosystems) and run on an ABI 3100 Automated Capillary DNA Sequencer. All newly generated sequences were deposited in GenBank (details in Table S1A and B). Orthologous sequences of Mimosestes ulkei (AB499964) and Donacia bicolor (EU880600) as well as Lysathia ludoviciana (EU682397) and Altica litigata (EU682395) were downloaded from GenBank and included as outgroups in the COI and ITS1 alignments, respectively.

\section{Data analysis}

The sequences were checked and aligned using BioEdit v.7.0.5.2 (Hall, 1999) and ClustalX (Thompson et al., 2002).

The sequences of presumed Wolbachia genes were compared with data in NCBI using the Basic Local Alignment Search Tool (BLAST) (Altschul et al., 1990) to check if primers amplified the targeted $\alpha$-proteobacteria. MLST analyses were executed in two steps: on (i) full-length sequences of all five genes generated from beetles, and (ii) shorter alignments due to the low quality of $\sim 20$ bp at 5' and 3' end of electropherograms of some sequences obtained from plant tissues (coxA - $559 \mathrm{bp}$, gatB - $332 \mathrm{bp}$, hcp $A$ $-508 \mathrm{bp}, f p b A-356 \mathrm{bp}$, fts $Z-368 \mathrm{bp}$ ).

Due to the presence of double infection in the majority of the specimens, sequences from all double infected specimens were amplified using both the A and B specific primer sets. This approach allowed for the collection of alleles of all five MLST genes from the specimens examined. We assumed that all alleles belonging to the A super group were generated from a single A strain present in all the individuals, and that all alleles belonging to the B super group were also generated from a single B strain present in all individuals. Finally, allelic profiles of MLST genes were generated for each individual. Similarly, A and B specific primers were used on DNA isolates obtained from host plants and the above procedure was used to generate allelic profiles (however for plant samples only super group A was found).

Next, we utilized an approach similar to that of Montagna et al. (2014) to compare allelic profiles generated from Crioceris beetles with some representative sequence types from other species that harboured bacteria belonging to the super groups: A (ST-1 from Drosophila melanogaster), B (ST-15 from Drosophila simulans), D (ST-35 from nematode), F (ST-8 from Cimex lectularius), and $\mathrm{H}(\mathrm{ST}=90$ from Zootermes angusticollis). Moreover, the allelic profiles found in the weevil Eusomus ovulum [which occupies the same habitat as infected Crioceris species (Mazur et al., 2016)] and in Oreina cacaliae [the only European leaf beetle with a full allelic profile in the MLST database (Montagna et al., 2014)] were added to this set of MLST sequences. We then used the generated alignment of MLST genes for the construction of phylogenetic trees starting with two datasets: (i) full-length sequences from Crioceris and MLST database references; (ii) shorter alignments that included strains found in Crioceris and Asparagus tissues. Phylogenetic trees were inferred using Maximum Likelihood (ML) implemented in PhyML 3.0 (Guindon et al., 2010) using the web-page interface http://www.atgc-montpellier.fr/phyml/. The beta version of the program was used, which includes automatic selection of the best DNA substitution model - Smart Model Selection (http://www.atgc-montpellier.fr/sms/) with the use of the Akaike Information Criterion (AIC). Branch support was obtained using the approximate Likelihood-Ratio Test (aLRT SH-like) (Anisimova \& Gascuel, 2006).

In order to exclude COI and ITS1 tree topology artefacts due to saturation, the alignments were inspected in DAMBE (Xia, 2013). The test for saturation showed that the level of saturation was very low both in COI (Iss $=0.16<$ Iss.c. $=0.75$ ) and ITS1, both when including (Iss $=0.54<$ Iss.c $=0.74$ ) and excluding indels (Iss $=0.14<$ Iss.c. $=0.72$ ). Phylogenetic trees for COI 
and ITS1 alignments were inferred using the ML implemented in PhyML 3.0 under the settings described above. Only unique haplotypes of either COI or ITS1 were used for tree reconstruction.

\section{RESULTS}

Wolbachia was detected exclusively in C. 14-punctata and C. 5-punctata (Fig. S1). Amplification succeeded in all six of the populations of both species analyzed (19 specimens for C. 14-punctata and 10 for C. 5-punctata). Wolbachia sequences belonging to $\mathrm{A}$ and $\mathrm{B}$ super groups were detected in all individuals of both species (Fig. 2), indicating double infection in all individuals. It is noteworthy that at each site randomly collected individuals harboured the same strains of Wolbachia.

The allelic profiles obtained from infected species of Crioceris did not have identical profiles in the MLST database (obtained on the 02-12-2016). Strain A was identical in three genes ( gatB - allele no 32, cox $A$ - allele 33, fts $Z$ - allele 154), whereas $h c p A$ and $f b p A$ differed by $1 \%$ from most similar alleles in the MLST database; while, strain $\mathrm{B}$ was identical in four genes ( $h c p A-$ allele 227, coxA allele $9, f t s Z$ - allele $8, f b p A$ - allele 246), whereas gat $B$ differed by $1 \%$ from the most similar alleles in the MLST database. Thus, the strain A alleles were most similar to ST 65, 66, 348 and 355 known from American spiders Agelenopsis aperta and Agelenopsis naevia and the European

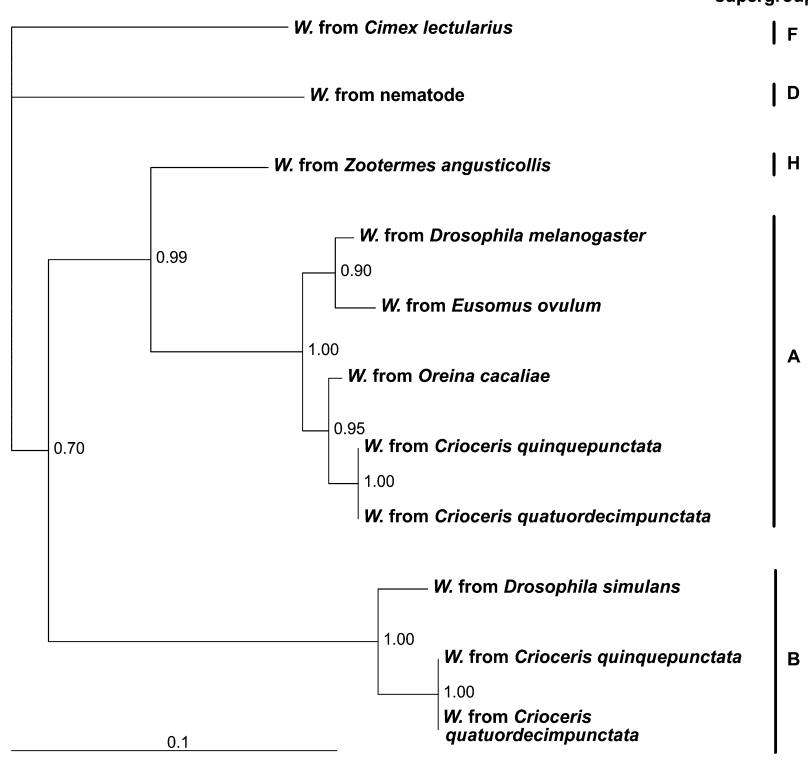

Fig. 2. Maximum likelihood phylogenetic tree inferred on the basis of five Multilocus Sequence Typing genes used for the genotyping of Wolbachia, amplified using DNA obtained from infected Crioceris leaf beetles and compared with several profiles of sequence types specific for the particular super groups: A - Drosophila melanogaster, B - Drosophila simulans, D - nematode) F - Cimex lectularius, and $\mathrm{H}-$ Zootermes angusticollis. Moreover, the allelic profiles found in the weevil Eusomus ovulum and Oreina cacaliae were added for comparison.

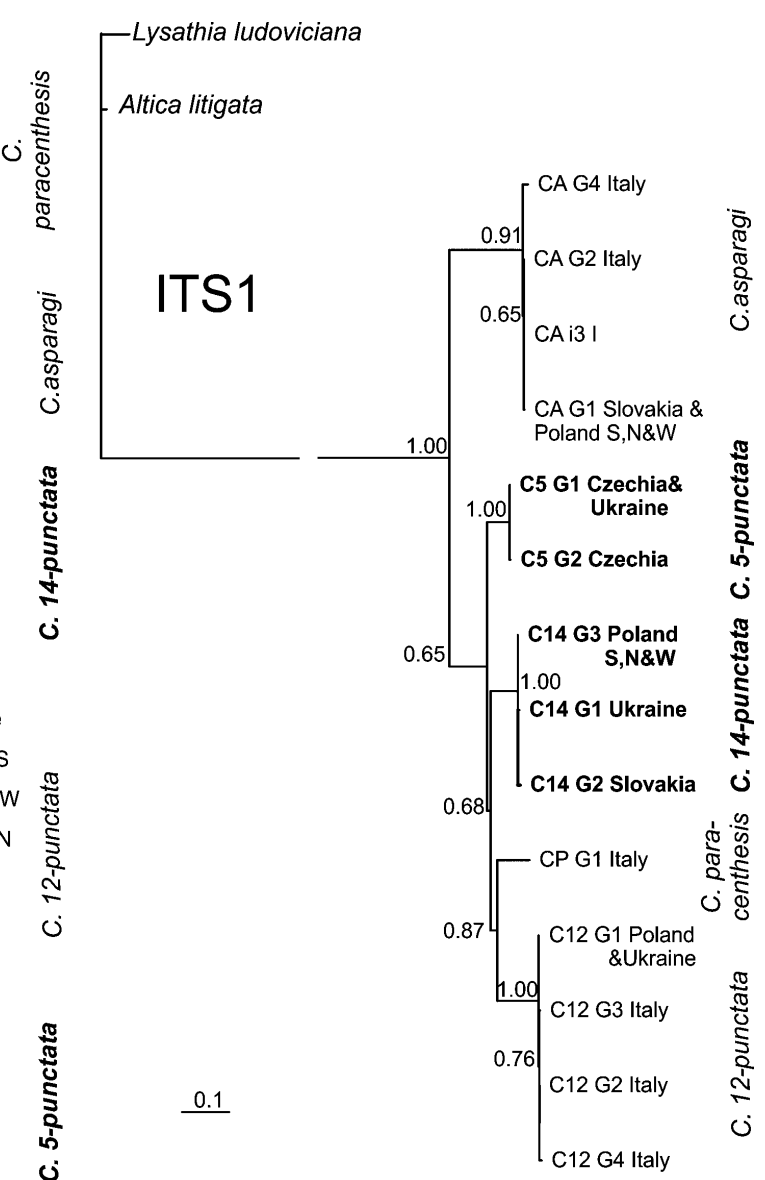

Fig. 3. Maximum likelihood phylogenetic trees of the five species of Crioceris studied inferred on the basis of two markers: Cytochrome Oxidase subunit I gene of mitochondrial DNA (COI) and Internal Transcribed Spacer 1 of nuclear ribosomal DNA (ITS1). Wolbachia infected specimens in bold. $\mathrm{H}$ - COI haplotypes, G - ITS1 haplotypes, Poland S, N and W - Polish populations from southern, northern and western part of the country (see Table 1 for details). Numbers above the branches indicate statistical measures of nodal support. 
weevil Ceutorhynchus obstrictus; whereas, strain B was most similar to ST 37, which is known from the Palearctic wasps Polistes dominulus and Tetrastichus coeruleus, the Southasian butterfly Anthene emolus and the Eurasian butterflies Erebia aethiops and Neptis rivularis.

Wolbachia genes were also detected via PCR amplification in some leaves and stems of the host plants collected during the reproductive period of Crioceris beetles, however, none were amplified from DNA extracted from the host plant roots (Fig. S1). Plants from which Wolbachia genes were amplified were collected at Skowronno, southern Poland, and at Grabowo, northern Poland, where $C$. 14-punctata was allopatric (Skowronno) or sympatric (Grabowo) with C. 12-punctata. No amplification was recorded for plants collected where only C. 12-punctata was present (Wiślica). Finally, we failed to amplify $\mathrm{Wol}$ bachia genes in samples taken from the same host plants after the reproductive period of Crioceris (Skowronno). Sequences of Wolbachia genes generated from host plant isolates belonged exclusively to super group A and clustered with sequences obtained from C. 14-punctata (Fig. S2). In northern Poland (Grabowo), a further Wolbachia MLST haplotype was amplified in addition to the one identical to that found in the beetles (Fig. S2). These different sequences were $0.9 \%(\operatorname{cox} A), 3.1 \%($ gat $B), 3.0 \%(h c p A)$, $1.1 \%(f t s Z)$ and $6.3 \%(f b p A)$ nucleotide divergent from the A allele amplified from C. 14-punctata and C. 5-punctata. Based on shorter sequences, the only sequence that the distinct A strain found in plant tissues had that was identical to the MLST sequences was fts $Z$ (allele 165), which is known from ST 337, isolated from an unspecified host.

Each of the species of Crioceris examined was found to be monophyletic and well supported (all aLRT larger than 0.95 ) based on both COI and ITS1 markers (Fig. 3). However, the topology of the two trees was not congruent (Fig. 3). According to the COI tree the only highly supported clade $($ aLRT $=0.89)$ grouped $C .14$-punctata and C. 12-punctata. Contrary to this, ITS1 tree supported $C$. 12-punctata as the sister of $C$. paracenthesis $(\mathrm{aLRT}=0.87)$ and both of these as sisters to C. 14-punctata (aLRT = 0.68). The group composed of the previous resulted sister of C. 5-punctata $($ aLRT $=0.65)$.

\section{DISCUSSION}

The results indicate that the bacterium Wolbachia is only present in two of the five species of Crioceris studied (i.e., in C. 5-punctata and C. 14-punctata). In addition, all of the populations of these two species tested positive for the bacterium, while the other species were not infected at any of the localities from which they were collected, both in central-eastern Europe and Italy. This finding is curious, as the two infected species are not sister taxa based on the ML analyses of mtDNA and nuclear rDNA. On the other hand, both species from all the populations harbour the same two strains belonging to both the A and B super groups. As Wolbachia is known to be transovarially transmitted (Yen, 1975), its presence in a group of species could be related with the phylogenetic relationships of the hosts, resulting in a cocladogenetic pattern. Two possible scenarios could explain the observed pattern of infection among Crioceris beetles: (i) the infection by Wolbachia occurred in the ancestor of the species analyzed, with maintenance in $C$. 5-punctata and C. 14-punctata; or (ii) the infection of these two species by Wolbachia is mediated by environmental factors, possibly through the host plant, since both species inhabit the same habitat (steppes and xeric grasslands) and have the same host plant (Asparagus spp.). However, even if the other members of the genus also feed on asparagus and can be found in xeric grasslands, this habitat does not represent the preferred habitat of C. 12-punctata and $C$. asparagi since these species occur widespread on asparagus, especially cultivated plants. The other species analyzed, C. paracenthesis, is more Mediterranean and the co-occurrence of this taxon with infected species is very rare. Regardless of these two hypotheses about the spread of Wolbachia in Crioceris, it is not easy to explain why some species are infected, whereas others are not. Similar patterns in the presence-absence of Wolbachia in a group of closely related species occur in other leaf beetles, for example, in species of the genus Altica (Jäckel et al., 2013), Oreina (Montagna et al., 2014), Chelymorpha (Keller et al., 2004), Diabrotica (Roehrdanz \& Sears Wichmann, 2013; Roehrdanz \& Wichmann, 2014) and Callosobruchus (Kondo et al., 1999). However, none of these studies investigated infection with respect to susceptibility or resistance of the hosts. Sensitivity or immunity to infection could be tested, but this would not be possible for the two infected Crioceris species since they are very rare and threatened in nature, and are also unlikely to be easily artificially reared since they inhabit steppes and are highly stenotopic (Kubisz et al., 2011; Mazur et al., 2014). The sharing of the same habitat (steppes and xeric grasslands) by both mediated species suggests that their infection could be mediated by a common environment, as is suggested for some other communities (e.g. for Diptera living on mushrooms; Stahlhut et al., 2010).

Our study, even if preliminary and based on a small sample size, shows that the infection of species of Crioceris is not dependent on the geography/location of populations, since the individuals of both infected and uninfected species analyzed came from distant populations. This result might indicate that some species of Crioceris could be bacteria-free because they have some mechanisms that make them immune to Wolbachia, whereas others are prone to being infected; however, this hypothesis requires further testing.

Although Wolbachia is currently one of the most intensively studied organisms due to its effect on its host's reproduction, demography and speciation (Werren, 1997), evidence for horizontal transmission through the digestive system was only published recently (e.g., Caspi-Fluger et al., 2012; Li et al., 2016). Our study, even if based on a small group of species, suggests that Wolbachia could be transmitted among insects that share the same environment, for example, through the exploitation of the same host plants. In fact, the DNA of the bacterium was detected in tissues 
of species of Asparagus at a time when the two species of Crioceris harbouring Wolbachia were feeding on these host plants. We only detected Wolbachia genes in plant tissues collected from locations where infected C. 14-punctata beetles occurred during their reproductive period, but not in plants where only uninfected C. 12-punctata were recorded. Moreover, we failed to amplify Wolbachia genes in plant tissues collected from a location with a known $C$. 14-punctata population, but after they had ceased reproducing. These observations seem to indicate that the bacterial DNA in the host plant tissues is related to feeding by infected beetles. It is important to highlight that not all of the Wolbachia alleles detected in plant tissues were the same or very similar to those obtained from beetles. This can be explained in several ways. It is notable that in plant tissues we only found bacterial strains from super group A even though populations of C. 14-punctata are infected by both super groups (Kubisz et al., 2011; Mazur et al., 2014). It is possible that we simply missed strains from super group B or that for some reason only bacteria from super group A can survive in plant tissues. Alternative explanations are that these two strains show different tissue tropisms and only the super group A strain is present in the saliva or that the super group B strain appears in a much lower titre than the other strain, and is therefore not transmitted to host plant tissues. Moreover, problems with the interpretation of Wolbachia sequences obtained from plant tissue may be a consequence of the degradation of the bacterial genome due to the inhospitable environment in plant tissues for exclusively endosymbiotic (intracellular) bacteria [Wolbachia could probably survive for a short time in plant tissues (e.g. in the phloem in the neighbourhood of beetle feeding)], but unable to live outside its beetle host (positive amplification of short sequences does not mean that live bacteria was present in plant tissues).

Detection of a different Wolbachia super group A strain in plant tissues also needs an explanation. The simplest is that this different strain could come from some other beetle (e.g. asparagus is the host plant for $6.5 \%$ of steppic leaf beetles, Kajtoch et al., 2015) or numerous other arthropods that feed on the same host plant, among which other species infected by different strains of Wolbachia can be expected. Therefore, bacterial genes could be transmitted to the host plant from other insects, and the sap-sucking bugs are the group that may be most responsible for this (Caspi-Fluger et al., 2012; DeLay et al., 2012). The possibility that Crioceris beetles could transmit Wolbachia to their host plants and vice versa, during feeding, requires further investigation.

ACKNOWLEDGEMENTS. This work was supported by grant DEC-2013/11/D/NZ8/00583 from the National Science Centre, Poland (to Ł. Kajtoch).

\section{REFERENCES}

Ahmed M.Z., Li S.-J., Xue X., Yin X.-J., Ren S.-X., Jiggins F.M., GreefF J.M. \& QIU B.-L. 2015: The Intracellular bacterium Wolbachia uses parasitoid wasps as phoretic vectors for effi- cient horizontal transmission. - PLoS Pathog. 11: e1004672, 19 pp.

Altschul S.F., Gish W., Miller W., Myers E.W. \& Lipman D.J. 1990: Basic local alignment search tool. - J. Mol. Biol. 215 : 403-410.

Anisimova M. \& Gascuel O. 2006: Approximate likelihood-ratio test for branches: a fast, accurate, and powerful alternative. Syst. Biol. 55: 539-552.

Baldo L., Hotopp J.C.D., Jolley K.A., Bordenstein S.R., Biber S.A., Choudhury R.R., Hayashi C., Maiden M.C.J., Tettelin H. \& Werren J.H. 2006: Multilocus sequence typing system for the endosymbiont Wolbachia pipientis. - Appl. Environ. Microbiol. 72: 7098-7110.

Breeuwer J.A.J., Stouthamer R., Barns S.M., Pelletier D.A., Weisburg W.G. \& Werren J.H. 1992: Phylogeny of cytoplasmic incompatibility microorganisms in the parasitoid wasp genus Nasonia (Hymenoptera: Pteromalidae) based on 16S ribosomal DNA sequences. - Insect Mol. Biol. 1: 25-36.

Caspi-Fluger A., Inbar M., Mozes-Daube N., Katzir N., Portnoy V., Belausov E., Hunter M.S. \& Zchori-Fein E. 2012: Horizontal transmission of the insect symbiont Rickettsia is plant-mediated. — Proc. R. Soc. Lond. (B) 279: 1791-1796.

Clark S.M., LeDoux D.G., Seeno T.N., Riley E.G., Gilbert A.J. \& Sullivan J.M. 2004: Host Plants of Leaf Beetles Species Occurring in the United States and Canada. Coleopterists Society Special Publication No. 2, Sacramento, CA, 615 pp.

Clec'h W.L., Chevalier F.D., Genty L., Bertaux J., Bouchon D. \& SiCARD M. 2013: Cannibalism and predation as paths for horizontal passage of Wolbachia between terrestrial isopods. - PLoS ONE 8: e60232, 6 pp.

Delay B., Mamidala P., Wijeratne A., Wijeratne S., Mittapalli O., WANG J. \& LAMP W. 2012: Transcriptome analysis of the salivary glands of potato leafhopper, Empoasca fabae. - J. Insect Physiol. 58: 1626-1634.

Fenton A., Johnson K.N., Brownlie J.C., Hurst G.D.D., HoffMANN A.E.A.A. \& BronsteIn E.J.L. 2011: Solving the Wolbachia paradox: modeling the tripartite interaction between host, Wolbachia, and a natural enemy. - Am. Nat. 178: 333342.

Gruev B. \& Doberl M. 2005: General Distribution of the Flea Beetles in the Palaearctic Subregion (Coleoptera, Chrysomelidae: Alticinae). Pensoft, Sofia, 239 pp.

Guindon S., Dufayard J.-F., Lefort V., Anisimova M., Hordijk W. \& GASCUEL O. 2010: New algorithms and methods to estimate maximum-likelihood phylogenies: assessing the performance of PhyML 3.0. - Syst. Biol. 59: 307-321.

Huigens M.E., Almeida R.P. De, Boons P.A.H., Luck R.F. \& Stouthamer R. 2004: Natural interspecific and intraspecific horizontal transfer of parthenogenesis-inducing Wolbachia in Trichogramma wasps. - Proc. R. Soc. Lond. (B) 271: 509515.

Huson D.H. \& Bryant D. 2006: Application of phylogenetic networks in evolutionary studies. - Mol. Biol. Evol. 23: 254-267.

Jäckel R., Mora D. \& Dobler S. 2013: Evidence for selective sweeps by Wolbachia infections: phylogeny of Altica leaf beetles and their reproductive parasites. - Mol. Ecol. 22: 42414255.

Johanowicz D.L. \& Hoy M.A. 1996: Wolbachia in a predatorprey system: 16S ribosomal DNA analysis of two phytoseiids (Acari: Phytoseiidae) and their prey (Acari: Tetranychidae). Ann. Entomol. Soc. Am. 89: 435-441.

Jolley K.A. \& MAiden M.C. 2010: BIGSdb: Scalable analysis of bacterial genome variation at the population level. - BMC Bioinformatics 11: 595, 11 pp. 
Kajtoch Ł., Kubisz D., Heise W., Mazur M.A. \& BabiK W. 2015: Plant-herbivorous beetle networks: Molecular characterization oftrophic ecology within a threatened steppic environment. Mol. Ecol. 24: 4023-4038.

Keller G.P., Windsor D.M., SAucedo J.M. \& Werren J.H. 2004: Reproductive effects and geographical distributions of two Wolbachia strains infecting the Neotropical beetle, Chelymorpha alternans Boh. (Chrysomelidae, Cassidinae). - Mol. Ecol. 13: 2405-2420.

Kondo N., Shimada M. \& FuKatsu T. 1999: High prevalence of Wolbachia in the Azuki bean beetle Callosobruchus chinensis (Coleoptera, Bruchidae). — Zool. Sci. 16: 955-962.

Kubisz D., Kajtoch Ł., Mazur M.A., Lis A. \& Holecová M. 2012a: Conservation genetics of highly isolated populations of the xerothermic beetle Crioceris quatuordecimpunctata (Chrysomelidae). - Invertebr. Biol. 131: 333-344.

Kubisz D., Kajtoch Ł., Mazur M. \& Rizun V. 2012b: Molecular barcoding for central-eastern European Crioceris leaf-beetles (Coleoptera: Chrysomelidae). - Centr. Eur. J. Biol. 7: 69-76.

LeSAge L., Dobesberger E.J. \& MaJKa C.G. 2008: Introduced leaf beetles of the maritime provinces, 6 : The common asparagus beetle, Crioceris asparagi (Linnaeus), and the twelve-spotted asparagus beetle, Crioceris duodecimpunctata (Linnaeus) (Coleoptera: Chrysomelidae). — Proc. Entomol. Soc. Wash. 110: 602-621.

Li S.-J., Ahmed M.Z., Lv N., Shi P.-Q., WANG X.-M., HuAng J.-L. \& QIU B.-L. 2016: Plant-mediated horizontal transmission of Wolbachia between whiteflies. - ISME J. 11: 1019-1028

Lindsey A.R., Bordenstein S.R., Newton I.L. \& RAsGon J.L. 2016: Wolbachia pipientis should not be split into multiple species: A response to Ramírez-Puebla et al., "Species in Wolbachia? Proposal for the designation of 'Candidatus Wolbachia bourtzisii', 'Candidatus Wolbachia onchocercicola', 'Candidatus Wolbachia blaxteri', 'Candidatus Wolbachia brugii', 'Candidatus Wolbachia taylori' 'Candidatus Wolbachia collembolicola' and 'Candidatus Wolbachia multihospitum' for the different species within Wolbachia supergroups". - Syst. Appl. Microbiol. 39: 220-222

Löbl I. \& Smetana A. 2010: Catalogue of Palaearctic Coleoptera: Chrysomeloidea. Vol. 6. Apollo Books, Stenstrup, 924 pp.

Mazur M.A., Kubisz D. \& KaJtoch Ł. 2014: Restricted geographic distribution and low genetic distinctiveness of steppic Crioceris quinquepunctata (Coleoptera: Chrysomelidae) populations in Central East Europe. - Entomol. Fenn. 25: 102-110.

Mazur M.A., Holecova M., Lachowska-Cierlik D., Lis A., Kubisz D. \& KaJtoch L. 2016: Selective sweep of Wolbachia and parthenogenetic host genomes - the example of the weevil Eusomus ovulum. - Insect Mol. Biol. 25: 701-711.

Mitsuhashi W., Saiki T., Wei W., Kawakita H. \& Sato M. 2002: Two novel strains of Wolbachia coexisting in both species of mulberry leafhoppers. - Insect Mol. Biol. 11: 577-584.

Monrós F. 1960: Los géneros de Chrysomelidae (Coleoptera). Opera Lilloana 3: 1-336.

Montagna M., Chouaia B., Sacchi L., Porretta D., Martin E., Giorgi A., Lozzia G.C. \& EpIS S. 2014: A new strain of Wolbachia in an Alpine population of the viviparous Oreina cacaliae (Coleoptera: Chrysomelidae). - Environ. Entomol. 43: 913-922.

Morin L. \& EDwArDS P.B. 2006: Selection of biological control agents for bridal creeper: a retrospective review. - Aust. $J$. Entomol. 45: 287-291.

Noda H., Miyoshi T., Zhang Q., Watanabe K., Deng K. \& HoshiZAKI S. 2001: Wolbachia infection shared among planthoppers (Homoptera: Delphacidae) and their endoparasite (Strepsiptera:
Elenchidae): a probable case of interspecies transmission. Mol. Ecol. 10: 2101-2106.

O’Neill S.L., Giordano R., Colbert A.M., Karr T.L. \& RobertSON H.M. 1992: 16S rRNA phylogenetic analysis of the bacterial endosymbionts associated with cytoplasmic incompatibility in insects. - Proc. Natl. Acad. Sci. 89: 2699-2702.

Ramirez-Puebla S.T., Servin-Garciduenas L.E., Ormeno-Orrillo E., Vera-Ponce de Leon A., Rosenblueth M., Delaye L., Martinez J. \& Martinez-Romero E. 2015: Species in Wolbachia? Proposal for the designation of 'Candidatus Wolbachia bourtzisii', 'Candidatus Wolbachia onchocercicola', 'Candidatus Wolbachia blaxteri', 'Candidatus Wolbachia brugii', 'Candidatus Wolbachia taylori' 'Candidatus Wolbachia collembolicola' and 'Candidatus Wolbachia multihospitum' for the different species within Wolbachia supergroups. - Syst. Appl. Microbiol. 38: 390-399.

Riegler M. \& O'NeILL S.L. 2006: The genus Wolbachia. In Dworkin M., Falkow S., Rosenberg E., Schleifer K. -H. \& Stackebrandt E. (eds): The Prokaryotes: Vol. 5: Proteobacteria: Alpha and Beta Subclasses. Springer, New York, pp. 547-561.

RoEhrdanz R.L. \& SEARs WichmanN S.G. 2013: Wolbachia wsp gene clones detect the distribution of Wolbachia variants and $w s p$ hypervariable regions among individuals of a multistrain infected population of Diabrotica barberi (Coleoptera: Chrysomelidae). - Ann. Entomol. Soc. Am. 106: 329-338.

ROEHRDANZ R.L. \& WichMANN S.S. 2014: Wolbachia multilocus sequence typing of singly infected and multiply infected populations of northern corn rootworm (Coleoptera: Chrysomelidae). - Ann. Entomol. Soc. Am. 107: 832-841.

Rousset F., Bouchon D., Pintureau B., Juchault P. \& Solignac M. 1992: Wolbachia endosymbionts responsible for various alterations of sexuality in arthropods. - Proc. R. Soc. Lond. (B) 250: 91-98.

Simon C., Frati F., Beckenbach A., Crespi B., Liu H. \& Flook P. 1994: Evolution, weighting, and phylogenetic utility of mitochondrial gene sequences and a compilation of conserved polymerase chain reaction primers. - Ann. Entomol. Soc. Am. 87: $651-701$.

Sintupachee S., Milne J.R., Poonchaisri S., Baimai V. \& KitTAYAPONG P. 2006: Closely related Wolbachia strains within the pumpkin arthropod community and the potential for horizontal transmission via the plant. - Microb. Ecol. 51: 294-301.

Stahlhut J.K., Desjardins C.A., Clark M.E., Baldo L., Russell J.A., WerRen J.H. \& JAENIKE J. 2010: The mushroom habitat as an ecological arena for global exchange of Wolbachia. - Mol. Ecol. 19: 1940-1952.

Stouthamer R., Breeuwer J.A J., Luck R.F. \& Werren J.H. 1993: Molecular identification of microorganisms associated with parthenogenesis. - Nature 361: 66-68.

Thompson J.D., Gibson T., Higgins D.G. 2002: Multiple sequence alignment using ClustalW and ClustalX. - Curr. Protoc. Bioinform. 2.3.1-2.3.22.

Van Meer M.M.M., Witteveldt J. \& Stouthamer R. 1999: Phylogeny of the arthropod endosymbiont Wolbachia based on the wsp gene. - Insect Mol. Biol. 8: 399-408.

Vavre F., Fleury F., Lepetit D., Fouillet P. \& Boulétreau M. 1999: Phylogenetic evidence for horizontal transmission of Wolbachia in host-parasitoid associations. - Mol. Biol. Evol. 16: 1711-1723.

WARCha£owsKi A. 1985: Chrysomelidae (Insecta: Coleoptera). Państwowe Wydawnictwo Naukowe, Warszawa, $261 \mathrm{pp}$.

WERREN J.H. 1997: Biology of Wolbachia. - Annu. Rev. Entomol. 42: 587-609. 
White T.J., Bruns T., Lee S. \& TaYlor J.W. 1990: Amplification and direct sequencing of fungal ribosomal RNA genes for phylogenetics. - PCR Protoc. Guide Meth. Appl. 18: 315-322.

XIA X. 2013: DAMBE5: A comprehensive software package for data analysis in molecular biology and evolution. - Mol. Biol. Evol. 30: $1720-1728$.
YeN J.H. 1975: Transovarial transmission of Rickettsia-like microoganisms in mosquitoes. - Ann. N. Y. Acad. Sci. 266: $152-161$.

Received May 16, 2017; revised and accepted September 26, 2017 Published online October 26, 2017

Table S1A. Accession numbers of Cytochrome Oxidade I (COI) and Internal Transcribed Spacer 1 (ITS1) sequences generated from Crioceris leaf beetles, deposited in GenBank (https://www.ncbi.nlm.nih.gov/genbank/) and used in the study.

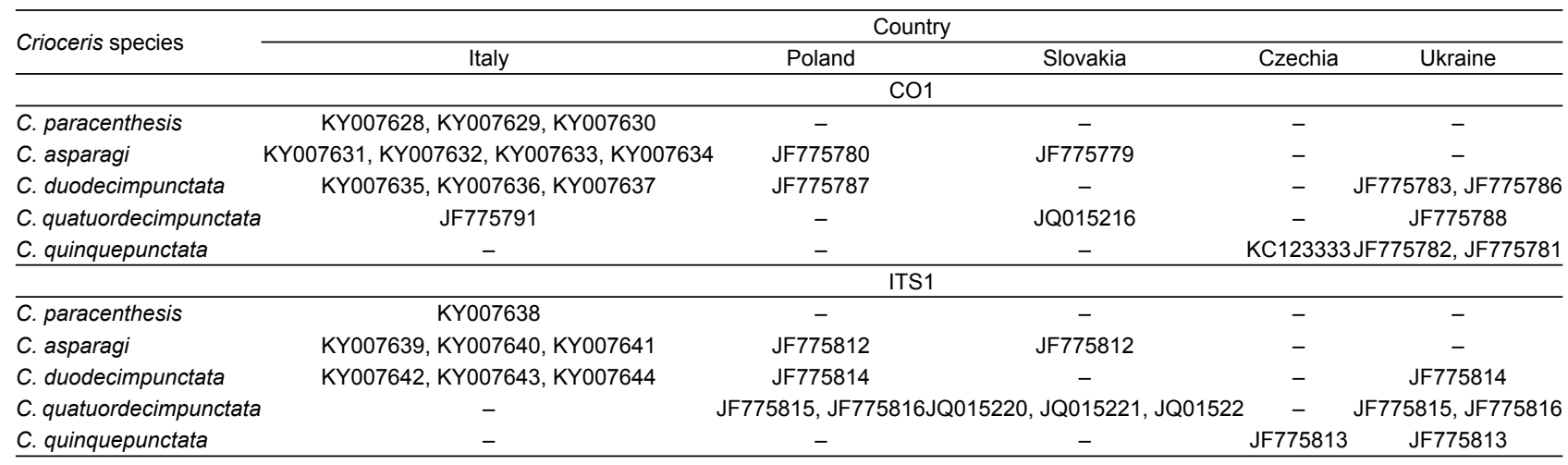

Table S1B. Accession numbers of Wolbachia genes from Multilocus Sequence Typing genotyping system generated from Crioceris leaf beetles and Asparagus host plants, deposited in GenBank (https://www.ncbi.nlm.nih. gov/genbank/) and used in the study.

\begin{tabular}{lrrr}
\hline GenBank Number & Gene & Organism & Supergroup \\
\hline KY316064 & coxA & Crioceris quatuordecimpunctata & B \\
KY316065 & coxA & Crioceris quatuordecimpunctata & A \\
KY316066 & coxA & Crioceris quinquepunctata & B \\
KY316367 & coxA & Crioceris quinquepunctata & A \\
KY316368 & coxA & Asparagus officinalis & A \\
KY316369 & coxA & Asparagus officinalis & A \\
KY316670 & coxA & Asparagus officinalis & A \\
KY316671 & fbpA & Crioceris quatuordecimpunctata & B \\
KY316672 & fbpA & Crioceris quatuordecimpunctata & A \\
KY316973 & fbpA & Crioceris quinquepunctata & B \\
KY317074 & fbpA & Crioceris quinquepunctata & A \\
KY317075 & fbpA & Asparagus officinalis & A \\
KY317076 & fbpA & Asparagus officinalis & A \\
KY317377 & fbpA & Asparagus officinalis & A \\
KY317378 & ftsZ & Crioceris quatuordecimpunctata & B \\
KY317379 & ftsZ & Crioceris quatuordecimpunctata & A \\
KY317680 & ftsZ & Crioceris quinquepunctata & B \\
KY317681 & ftsZ & Crioceris quinquepunctata & A \\
KY317682 & ftsZ & Asparagus officinalis & A \\
KY317983 & ftsZ & Asparagus officinalis & A \\
KY318084 & ftsZ & Asparagus officinalis & A \\
KY318085 & gatB & Crioceris quatuordecimpunctata & B \\
KY318086 & gatB & Crioceris quatuordecimpunctata & A \\
KY318387 & gatB & Crioceris quinquepunctata & B \\
KY318388 & gatB & Crioceris quinquepunctata & A \\
KY318389 & gatB & Asparagus officinalis & A \\
KY318690 & gatB & Asparagus officinalis & A \\
KY318691 & gatB & Asparagus officinalis & A \\
KY318692 & hcpA & Crioceris quatuordecimpunctata & B \\
KY318993 & hcpA & Crioceris quatuordecimpunctata & A \\
KY319094 & hcpA & Crioceris quinquepunctata & B \\
KY319095 & hcpA & Crioceris quinquepunctata & A \\
\hline
\end{tabular}

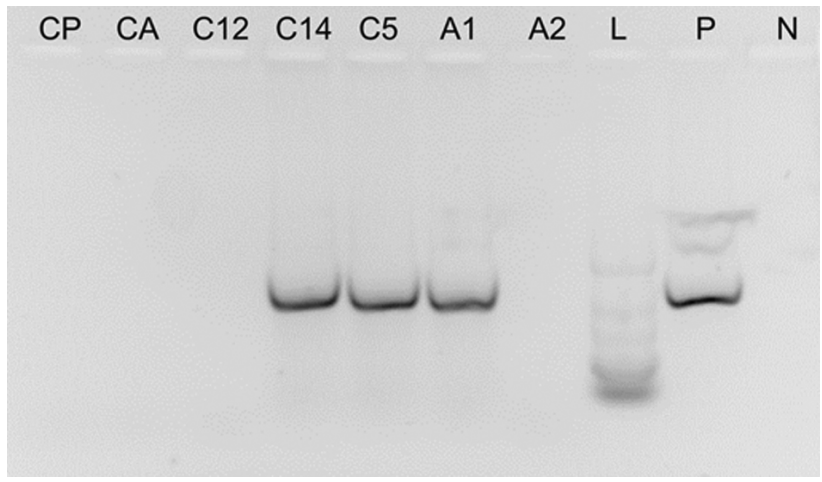

Fig. S1. Electrophoresis of products of the ftsZ gene amplification of isolates obtained from Crioceris leaf beetles (CP $-C$. paracenthesis, CA - C. asparagi, C12 - C. quatuordecimpunctata, C14 - C. duodecimpunctata, C5 - C. quinquepunctata) and their Asparagus officinalis host plants (A1 - sample from infected plant and A2 - uninfected plant). L - ladder, P - positive control (Polydrusus inustus), $\mathrm{N}$ - negative control (deionized water instead of DNA template). 


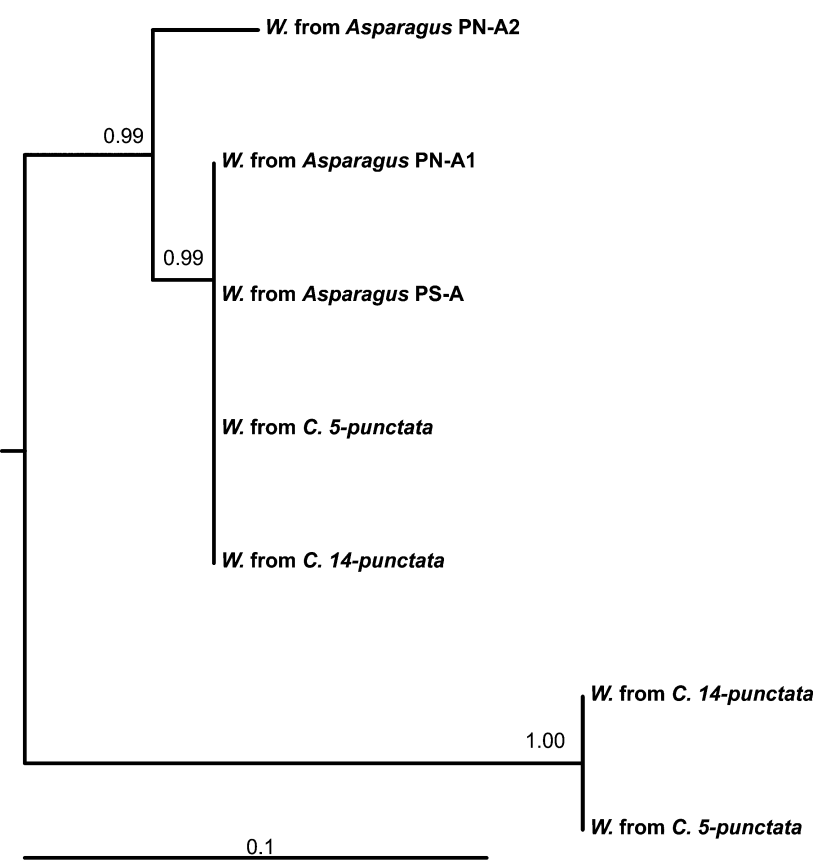

Fig. S2. Maximum likelihood phylogenetic tree inferred using the five Multilocus Sequence Typing genes used for genotyping Wolbachia, amplified using DNA obtained from infected Crioceris beetles and their Asparagus host plants. 